\title{
Katalog ksiąg sądowych Trybunału Koronnego Lubelskiego z 1598 roku
}

W księdze ziemskiej lubelskiej serii Inscriptiones z lat 1598-1600, sygn. 90, znajdują się dwa unikalne spisy, sporządzone z okazji objęcia przez Mikołaja Brodowskiego ${ }^{1}$ funkcji pisarza ziemskiego lubelskiego w 1598 roku, zawierające wykaz ksiąg sądów szlacheckich przechowywanych w archiwum ziemskim w Lublinie, mieszczącym się wówczas w refektarzu klasztoru oo. dominikanów. Pierwszy spis, zatytułowany Regestr odbierania ksiag przez urodzonego Pana Mikołaja Brodowskiego, pisarza ziemskiego lubelskiego, na pierwszej sesji, przez Pany Krzysztofa Wronowskiego i Stanisława Piczkowskiego, Komorniki ziemskie lubelskie, podanych, na leżeniu ksiag ziemskich $i$ na sadzeniu nowego lata $w$ Lublinie $w$ poniedziałek po święcie Podniesienia Krzyża Świętego roku Pańskiego 1598, został opublikowany i omówiony przez Justynę Kliszewską-Grechutę ${ }^{2}$. Drugi zaś spis, Catalogus actorum Juditioru[m] Tribuna[lis] Regni Lublini ab Anno 1579 celebratorum, zawierający wykaz ksiąg Trybunału Koronnego Lubelskiego z lat 1579-1598, nie doczekał się jak dotąd publikacji, a że na nią zasługuje, świadczy choćby fakt, że księgi Trybunału Koronnego spłonęły w, ,żelaznej sali” w Archiwum Głównym Akt Dawnych w Warszawie, w ostatnich dniach powstania warszawskiego ${ }^{3}$, gdzie przechowywane były od 1836 roku$^{4}$. W związku z powyższym, niniejszy spis stanowi niezwykle cenne źródło rzucające nieco światła nie tylko na funkcjonowanie Trybunału Koronnego

\footnotetext{
${ }^{1}$ Mikołaj Brodowski z Brodowa w latach 1598-1618 był pisarzem ziemskim lubelskim, zob.: Urzędnicy dawnej Rzeczypospolitej XII-XVIII wieku. Spisy, t. 4: Małopolska (województwa krakowskie, sandomierskie i lubelskie), z. 4: Urzędnicy województwa lubelskiego XVI-XVIII wieku. Spisy, oprac. W. Kłaczewski, W. Urban, Kórnik 1991, poz. 151.

${ }^{2}$ J. Kliszewska-Grechuta, Spis ksiag archiwum ziemskiego lubelskiego z 1598 roku, w: Archiwum Państwowe w Lublinie. Dzieje i zasób. Zbiór artykutów przygotowanych w zwiqzku z jubileuszem 80-lecia Archiwum, red. E. Wierzbicka, L. Zabielski, Warszawa 2003, s. 103-118.

${ }^{3}$ A. Stebelski, Dzieje zniszczenia Archiwum Głównego Akt Dawnych, w: Straty archiwów i bibliotek warszawskich w zakresie rękopiśmiennych źródet historycznych, t. 1, Warszawa 1957, s. 26-27.

${ }^{4}$ Archiwum Państwowe w Lublinie (dalej: APL), Trybunał Cywilny I Instancji w Lublinie [1809]1810-1876[1885] (dalej: TC), sygn. 10 - akta dotyczące transportu akt trybunalskich do Warszawy; APL, TC, sygn. 11, k. 1-23 - korespondencja Rabińskiego z lat 1835-1836; T. Mencel, Archiwum Akt Dawnych w Lublinie (1827-1887), ,Rocznik Lubelski”, t. 1, 1958, s. 25.
} 
jako sądu najwyższej instancji, lecz także na organizację pracy w kancelarii trybunalskiej ${ }^{5}$.

Trybunał Koronny (Iudicium Ordinarium Generale Tribunalis Regni) utworzony został w 1578 roku na sejmie walnym warszawskim, na którym to król Stefan Batory, jako iudex supremus, zrzekł się dotychczasowych uprawnień najwyższego sędziego na rzecz stanowego sądu szlacheckiego ${ }^{6}$. Trybunałowi na mocy niniejszej konstytucji podlegała tylko Korona. Miejscami posiedzeń sądów koronnych trybunalskich zostały: Piotrków dla Wielkopolski i Mazowsza, a Lublin dla Małopolski. W Lublinie sądzono sprawy z następujących województw: krakowskiego, sandomierskiego, ruskiego, podolskiego, lubelskiego, bełskiego, podlaskiego, a także Księstwa Oświęcimskiego i Zatorskiego?.

Pierwsza sesja niniejszego sądu odbyła się w 1579 roku$^{8}$. Omawiane źródło zawiera spis wszystkich ksiąg sądowych wytworzonych w wyniku prac Trybunału Koronnego Lubelskiego od początku jego funkcjonowania aż do 1598 roku, a więc do roku, w którym Mikołaj Brodowski objął nie tylko urząd pisarza ziemskiego lubelskiego, ale - zgodnie z „Ordynacją Trybunału Koronnego” z 1578 roku - także opiekę nad kancelarią trybunalską ${ }^{10}$. Należy dodać, że konstytucja z 1578 roku wyłączyła spod jurysdykcji Trybunału Koronnego Lubelskiego województwa wschodnie (bracławskie, kijowskie, wołyńskie) ${ }^{11}$. Dopiero od 1589 roku województwa bracławskie i wołyńskie przystępują do Trybunału Koronnego ${ }^{12}$, a rok później, tj. w 1590 roku, „za prośbą rad i posłów tych województw i zezwoleniem wszech stanów” przyłącza się województwo kijowskie ${ }^{13}$.

Trybunał rozpoczynał obrady w Piotrkowie, gdzie sądził od pierwszego poniedziałku po św. Marcinie (11 listopada) aż do Niedzieli Palmowej (Dominica Palmarum). W Lublinie rozpoczynał obrady od poniedziałku po pierwszej niedzieli po Wielkanocy (Dominica Conductus Paschae) aż do wyczerpania

${ }^{5}$ A. Myśliwiec, Organizacja i działalność kancelarii Trybunału Koronnego, Wybrane zagadnienia [w:] Trybunał w kulturze prawnej Rzeczypospolitej szlacheckiej, red. A. Dębiński, W. Bednaruk, M. Lipska, Lublin 2008, s. 71-92.

${ }^{6}$ Volumina Legum. Prawa, konstytucje i przywileje Królestwa Polskiego, Wielkiego Księstwa Litewskiego $i$ wszystkich prowincji należacych na walnych sejmach koronnych od Sejmu Wiślickiego roku pańskiego 1347 aż do ostatniego Sejmu uchwalone (dalej: VL), t. 2, s. 183; O. Balzer, Geneza Trybunału Koronnego. Studium z dziejów sądownictwa polskiego XVI wieku, Warszawa 1886, s. 234; W. Maisel, Trybunat Koronny w świetle laudów sejmikowych i konstytucji sejmowych, „Czasopismo Prawno-Historyczne", t. 34, 1982, z. 2, s. 73; W. Bednaruk, Trybunał Koronny. Szlachecki sad najwyższy w latach 1578-1794, Lublin 2008, k. 69

${ }^{7}$ VL, t. 2, s. 184; O. Balzer, dz. cyt., s. 321; W. Maisel, dz. cyt., s. 76-77.

${ }^{8}$ Księga z 1579 roku - APL, Księgi ziemskie lubelskie 1409-1810 (dalej: Kzl), sygn. 90, k. 430.

${ }^{9}$ VL, t. 2, s. 184; O. Balzer, dz. cyt., s. 321; W. Maisel, dz. cyt., s. 76-77.

${ }^{10}$ VL, t. 2, s. 402; M. Goyski, Reformy Trybunału Koronnego, Lwów 1909, s. 52-53; M. Stankowa, Ocalate fragmenty akt Trybunatu Koronnego Lubelskiego w Wojewódzkim Archiwum Państwowym w Lublinie (1578-1793), „Archeion”, t. 40, 1964, s. 110.

${ }^{11}$ VL, t. 2, s. 185; M. Goyski, dz. cyt., s. 7.

12 VL, t. 2, s. 282; M. Goyski, dz. cyt., s. 8.

${ }^{13}$ VL, t. 2, s. 315; M. Goyski, dz. cyt., s. 8. 
wszystkich spraw wniesionych w danym roku ${ }^{14}$, co zwykle trwało do św. Bartłomieja (24 sierpnia) $)^{15}$.

Katalog ksiag sadowych Trybunatu Koronnego w Lublinie obejmuje w sumie 89 ksiąg z lat 1579-1586 i 1589-1598. Zawiera on wykaz ksiąg sądowych trybunalskich, w którym zastosowano układ rzeczowo-chronologiczny, a więc w trakcie przygotowywania spisu w obrębie danej serii zachowano porządek chronologiczny ksiąg sporządzonych w danym roku sesji trybunalskiej. W obrębie roku obowiązywał następujący porządek poszczególnych serii: najpierw spisywane były księgi serii iuditia, następnie ex officio causarum, a na końcu zaś inscriptionum et recognitionum.

W ramach serii iuditia obowiązywał podział na subserie, którego kryterium stanowiło pochodzenie spraw z terenu danego województwa. Księgi serii iuditia, czyli tzw. akta sądowe, zawierały wpisy o charakterze spornym ${ }^{16}$, np. decreta, iuramenta, protestationes, contumationes, condemnationes, contoversiae (motiones). W obrębie serii iuditia konsekwentnie stosowano najpierw układ chronologiczny uwzględniający wyłuszczone tytuły zawierające datę roczną, a następnie podział na podserie, których wyznacznikiem była skrócona nazwa województwa, co świadczyło, że dana księga zawierała wyroki spraw sądzonych z rejestru spraw danego województwa.

Księga obejmowała sprawy jednego, dwóch, a nawet trzech województw. Już w drugim roku pracy kancelarii trybunalskiej wytworzyła się praktyka łączenia spraw następujących województw: krakowskiego z sandomierskim ${ }^{17}$, podolskiego z lubelskim i bełskim ${ }^{18}$ lub podolskiego z lubelskim, a bełskiego z podlaskim ${ }^{19}$ oraz ruskiego z wołyńskim ${ }^{20}$, która prawdopodobnie wynikała także z faktu kolejności sądzenia spraw umieszczonych w poszczególnych rejestrach ${ }^{21}$.

Bezpośrednio po serii iuditia umieszczana była druga seria - ex officio causarum $^{22}$, obejmująca sprawy starostów i urzędników grodzkich winnych niedopełnienia bądź naruszenia swoich obowiązków przy sprawowaniu wymiaru sprawiedliwości, a zwłaszcza przy wykonywaniu egzekucji wyroków, także trybunalskich. Ex officio causarum jako odrębna seria pojawiła się dopiero w 1590 roku. Wpisy w danej serii zaczynały się datą początkową pierwszej księgi wojewódzkiej, a kończyły końcową datą ostatniej księgi wojewódzkiej danego roku. Wpisy wcześniejsze danej serii, sporządzone między 1579 a 1590 rokiem, wpisywano do ostatniej księgi

${ }^{14}$ VL, t. 2, s. 184; O. Balzer, dz. cyt., s. 323; M. Goyski, dz. cyt., s. 32.

${ }^{15}$ O. Balzer, dz. cyt., s. 323; M. Goyski, dz. cyt., s. 32. Precyzyjne daty końca lubelskich kadencji z lat 1579-1598 znamy dzięki omawianemu Katalogowi - APL, Kzl, sygn. 90, k. 430-434.

${ }^{16}$ S. Kutrzeba, Historia źródet dawnego prawa polskiego, t. 1, Lwów 1925, s. 140.

${ }^{17}$ Księgi z lat: 1582, 1583 i 1585 - APL, Kzl, sygn. 90, k. 430-430v.

${ }^{18}$ Księgi z lat: 1580, 1582-1586, 1589-1590 i 1597 - APL, Kzl, sygn. 90, k. 430, 430v, 431-432, $433 \mathrm{v}, 434$.

${ }^{19}$ Księga z 1593 roku - APL, Kzl, sygn. 90, k. 433v.

${ }^{20}$ Księga z 1597 roku - APL, Kzl, sygn. 90, k 434.

${ }^{21}$ Dopiero „Ordynacja Trybunału Koronnego ” z 1670 roku podjęła kwestię uporządkowania biegu spraw przez zaprowadzenie stałych terminów ich sądzenia - VL, t. 5, s. 32-34.

${ }^{22}$ Wyjątek stanowi układ ksiąg z 1597 roku - APL, Kzl, sygn. 90, k 434. 
wojewódzkiej serii iuditia. W Konsygnacji Piotra Zagrobskiego ${ }^{23}$ księgi trybunalskie, zaliczone do serii „Dekretów”, w ramach jednego roku obejmują zawsze o jeden wolumen więcej niż suma ksiąg wojewódzkich serii decretorum z Katalogu. Tą dodatkową księgą mogła być tylko ta, która zawierała wpisy ex officio causarum. Za tym, że były to księgi wyroków, przemawia również ich stałe miejsce za serią decretorum, a także ramy chronologiczne poszczególnych tomów.

Natomiast seria inscriptionum ${ }^{24}$ et recognitionum ${ }^{25}$ zawierała wpisy spraw o charakterze niespornym ${ }^{26}$. Wpisywano do nich akty woli jedno- lub dwustronne, dotyczące transakcji gruntowych lub kredytowych. Zapisy tego typu można także podzielić ze względu na czas trwania mocy prawnej danego wpisu, tj. akta o charakterze wieczystym, zwane perpetuitatum (darowizny, cesje, zrzeczenia, kupno, sprzedaż), oraz akta o charakterze czasowym, zwane obligationum (zastawy dóbr, kontrakty dzierżawne dóbr, skrypty dłużne, pokwitowania długów). Księgi inscriptionum et recognitionum obejmowały $\mathrm{z}$ reguły wpisy $\mathrm{z}$ dwóch lat ${ }^{27}$. W tym przypadku daty skrajne pokrywały się z początkową datą pierwszej księgi wojewódzkiej $\mathrm{z}$ roku poprzedniego i ostatnią datą ostatniej księgi wojewódzkiej roku bieżącego, czyli tego, pod którym wpisano księgę.

Wszystkim księgom w obrębie danej serii został nadany układ chronologiczny, tj. według terminów odbywających się sesji sądowych, co stanowiło odzwierciedlenie zasad, jakie obowiązywały w praktyce nie tylko sądu trybunalskiego, ale także kancelarii trybunalskiej.

Poszczególne księgi ujęte w Katalogu opisywano w następujący sposób: na lewym marginesie umieszczano serię ksiąg, a w przypadku iudita - skrót nazwy województwa, którego księga dotyczyła. Następnie wpisywano daty skrajne danej księgi. Były one zapisywane według kalendarza kościelnego. Czasem data była poprzedzona rozwinięciem tytułu księgi. Na prawym marginesie zaś - numeracja ksiąg, nadana w obrębie danego roku. Niewykluczone, że numery te nadano księgom już po sporządzeniu Katalogu, o czym świadczy ciemniejszy atrament.

Wykaz został spisany w języku łacińskim. Nazwa tytułu księgi oraz rok zostały wyróżnione pismem o wyższym module i szerszej linii. Należy dodać, że księga, w której znajduje się omawiany przez nas Katalog, była poddana konserwacji ze

${ }^{23}$ APL, TC, sygn. 41, s. 70-71, Konsygnacja akt dawnych polskich z całego województwa w mieście Lublinie skoncentrowanych w roku 1832 uformowana sporzadzona przez Piotra Zagrobskiego.

${ }^{24}$ Piotr Zagrobski definiuje serię Inscriptionum jako „obejmującą w sobie sprzedaże i kupno dóbr, wyroki zjazdowe i kompromissarskie, rozgraniczenia jednych dóbr od drugich, przywileje, działy dóbr, zapisy sum, roboracje kontraktów, ugód, intercyz, kwity, pełnomocnictwa, wizje, pozwy i manifesta", APL, TC, sygn. 41, s. 58. J. Bielecka, Inwentarze ksiagg archiwów grodzkich i ziemskich Wielkopolski XIV-XVIII wieku. Województwo poznańskie, kaliskie, gnieźnieńskie, inowrocławskie, Poznań 1965, s. 37.

${ }^{25}$ J. Bielecka, dz. cyt., s. 35.

${ }^{26}$ S. Kutrzeba, dz. cyt., s. 140; Historia państwa i prawa Polski, red. J. Bardach. Z. Kaczmarczyk, B. Leśnodorski, T. 2, Od połowy XV wieku do roku 1795, Warszawa 1971, s. 152.

${ }^{27}$ Wyjątki stanowią: księga z 1579 roku dotycząca tylko tego roku, księga wpisana pod rokiem 1597, obejmująca trzy lata (1595-1597), oraz księga z 1598 roku dotycząca tegoż roku. 
względu na zły stan zachowania. W związku z powyższym w tekście występują liczne uzupełnienia, szczególnie w okolicach zewnętrznych marginesów.

Katalog wraz ze Spisem ksiag ziemskich zostały uwierzytelnione nie tylko ręcznymi podpisami osób biorących udział w przejmowaniu ksiąg, a więc głównego zainteresowanego Mikołaja Brodowskiego, pisarza ziemskiego lubelskiego, i dwóch komorników ziemskich lubelskich: Krzysztofa Wronowskiego i Stanisława Rączki Piczkowskiego, lecz także dwiema pieczęciami papierowo-woskowymi. Pierwsza należała do pisarza ziemskiego lubelskiego i jest częściowo nieczytelna. Druga jest zaś w całości nieczytelna.

Przygotowując tekst do druku, zastosowano się do zaleceń Instrukcji wydawniczej dla źródel historycznych od XVI do połowy XIX wieku ${ }^{28}$. Układ graficzny Katalogu starano się oddać zgodnie z oryginałem, zachowując prawy i lewy margines oraz część centralną tekstu. Serie ksiąg, rok czy też liczba porządkowa ksiąg w obrębie roku, zapisane na marginesach, w wielu miejscach uległy uszkodzeniu na skutek zniszczenia kart. Uszkodzone miejsca tekstu zostały odtworzone i zapisane w nawiasach kwadratowych, ,[]”. W podobny sposób zaznaczano rozwinięcia skrótów. Dla odróżnienia uzupełnień tekstu spowodowanych uszkodzeniem tekstu od rozwinięcia skrótów zastosowano przypisy. Wprowadzono własną interpunkcję, gdyż była ona mało widoczna w tekście. Kursywą podano rozwiązane daty kalendarza kościelnego oraz własne objaśnienia. Zachowano oryginalny zapis liter „,j” oraz „v" w łacińskich słowach juditia, vno. Konsekwentnie stosowanymi skrótami w tekście Katalogu są: „D.” dla dominica, „S.” dla sanctus, Santa czy „SS” dla sancti, sanctae. Ograniczono pisownię dużych liter, dostosowując ją do współczesnej ortografii.

\section{Tekst źródłowy}

\section{[k. 430] \\ Cathalogvs Actorum Juditioru[m] Tribunal[is] Regni Lublini ab Anno 1579 celebratorum. \\ In primis eodem 1579 Anno, vigore Constitutionis eo nomine laudatae Ju- ditia Generalia Tribunal[is] Regni Minor[is] Poloniae su[n]t Lublini celebrata Palatinatuu[m] Cracovien[sis], Sandomir[iensis] et Rusiae tantum eorundem- que Juditior[um] Acta p[rae]dictor[um] Palatinatuu[m] eo m[od]o sequ[n]t[ur].}

Crac[oviensis] Palatinatus Acta inchoata feria secunda post Dominicam Conductus Paschae [27 IV] Anno supra[scri]pto 1579. Determinata v[er]o feria tertia $\mathrm{p}[\mathrm{o}] \mathrm{s}[\mathrm{t}]$ Dominicam Cantate [19 V].

${ }^{28}$ Instrukcja wydawnicza dla źródet historycznych od XVI do połowy XIX wieku, przedm. K. Lepszy, Wrocław 1953. 


\begin{tabular}{|c|c|}
\hline Sandomirien[sis] & $\begin{array}{l}\text { Inchoata feria qvarta post eandem Dominicam } \\
\text { Cantate }[20 \mathrm{~V}] \text {. Continuata vero in crastino festi } \\
\text { Sancti Joannis Baptistae }[25 \mathrm{VI}] \text {. }\end{array}$ \\
\hline Rusiae & $\begin{array}{l}\text { Inchoata fe[ri] a sexta post hoc ibidem festum } \\
\text { S[an]cti Joannis Bapt[ista]e [26 VI]. Continuata } \\
\text { v[er]o feria quinta post festum S[an]cti Jacobi } \\
\text { Ap[osto]li [30 VII], in eisdemque Actis } \\
\text { limit[ati]o Causarum reliquorum Palatinatuu[m] } \\
\text { continet[um]. }\end{array}$ \\
\hline Inscriptionum & $\begin{array}{l}\text { et aliar[um] recognitionum coram eodem } \\
\text { Judi[ti]o A[nn]o eodem recognitar[um]. Inchoata } \\
\text { feria } 2 \text { da post Dominicam Conductus Paschae } \\
{[27 \mathrm{IV}] \text {. Continuata v[er]o feria 3a post festu[m] }} \\
\text { S[an]cti Jacobi [28 VII]. }\end{array}$ \\
\hline An[no] 1580 & $\begin{array}{l}\text { Judi[ti]a Palatinatuu[m] Rusiae Po[do] }]^{\mathrm{c} l i a e} \\
\text { Lublinen[sis] Belzen[sis] et Podlachiae expedita } \\
\text { et Crac[oviensis] inchoat[a]. [k. } 430 v] \text { Quorum } \\
\text { Palatinatuu[m] Acta eo ordine sequntur. }\end{array}$ \\
\hline Rusiae & $\begin{array}{l}\text { Pars prima inchoata feriae se[cun]dae post } \\
\text { D. Conductus Paschae }[11 \mathrm{IV}] \text {, determinata } \\
\text { v[er]o fe }[\text { ri }] \text { a tertia post } \mathrm{D} \text {. Cantate }[3 \mathrm{~V}] \text {. }\end{array}$ \\
\hline$\left[{ }^{\mathrm{d}}\right]$ & $\begin{array}{l}\text { Secunda v[er]o pars inchoata fe[ri]a teria } \\
\text { p[o]s[t] eand[em] Dominic[am] }[3 \mathrm{~V}] \text {, determinata } \\
\text { v[er]o post Dominicam Exaudi }[p o \quad 15 \mathrm{~V}]\end{array}$ \\
\hline$[\mathrm{Po}]^{\mathrm{e}}$ doliae & Vnius volumnis. Inchoata ead[em] sabbato post \\
\hline $\begin{array}{l}\text { Lub[li]nen[sis] et } \\
\text { Belzen[sis] }\end{array}$ & $\begin{array}{l}\text { Domini }[\mathrm{cam}] \text { eand }[\mathrm{em}][21 \mathrm{~V}] \text {. Determinata } \\
\text { v[er]o fe[ri]a } 2 \text { ante festum S. Jo[anni]s Bapt[ist]ae } \\
{[20 \mathrm{VI}] .}\end{array}$ \\
\hline$[\mathrm{P}]^{\mathrm{f}}$ odlachiae & $\begin{array}{l}\text { Inchoata eadem feria s[e]c[un]da ante festum } \\
\text { S[an]cti Joannis [20 VI]. Determinata v[er]o sabbato } \\
\text { in crast[in]o festi Divisionis S[an]ctor[um] } \\
\text { Ap[osto]loru[m] [16 VII]. }\end{array}$ \\
\hline
\end{tabular}

${ }^{\mathrm{a}} \mathrm{W}$ tym miejscu występuje uszkodzenie marginesu karty.

${ }^{\mathrm{b}} \mathrm{W}$ tym miejscu występuje uszkodzenie marginesu karty.

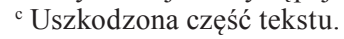
chodzi.

${ }^{\mathrm{d}} \mathrm{W}$ tym miejscu występuje uszkodzenie marginesu karty. Trudno określić, o jakie województwo

${ }^{\mathrm{e}} \mathrm{W}$ tym miejscu występuje uszkodzenie marginesu karty.

${ }^{\mathrm{f}} \mathrm{W}$ tym miejscu występuje uszkodzenie marginesu karty. 
Cracovi[ensis] Inchoata fe[ri]a 2 post festu[m] Divisio[n]is $\mathrm{S}$.

Ap[osto]lorum prox[im]a [18 VII]. In eode[m]que volumine continent[ur] Acta eiusde[m] Palatinatus Crac[oviensis] atq[ue] Sandomi[riensis] Anni 1581 expedit[is]. Determinataq[ue] ead[em] Acta fe[ri]a qvinta post Do[min]icam Cantate A[nn]o 1581 [27 IV].

\section{$[A]^{\mathrm{g} n}[\mathbf{n o}] \mathbf{1 5 8 1}$}

$[\mathrm{R}]^{\mathrm{h}}$ usiae

$$
\begin{aligned}
& \text { Juditia eadem sunt celebrata Palatinatuu[m] } \\
& \text { Crac[oviensis], Sandomir[iensis], Rusiae, } \\
& \text { Podoliae, Lublinen[sis], Belzen[sis], Podlachiae. } \\
& \text { Quor[um] duor[um] Palatinatuu[m] Acta videlicet } \\
& \text { Cracovien[sis] et Sandomir[iensis] in volumine } \\
& \text { sup[er]ius descripto continet[ur]. }
\end{aligned}
$$

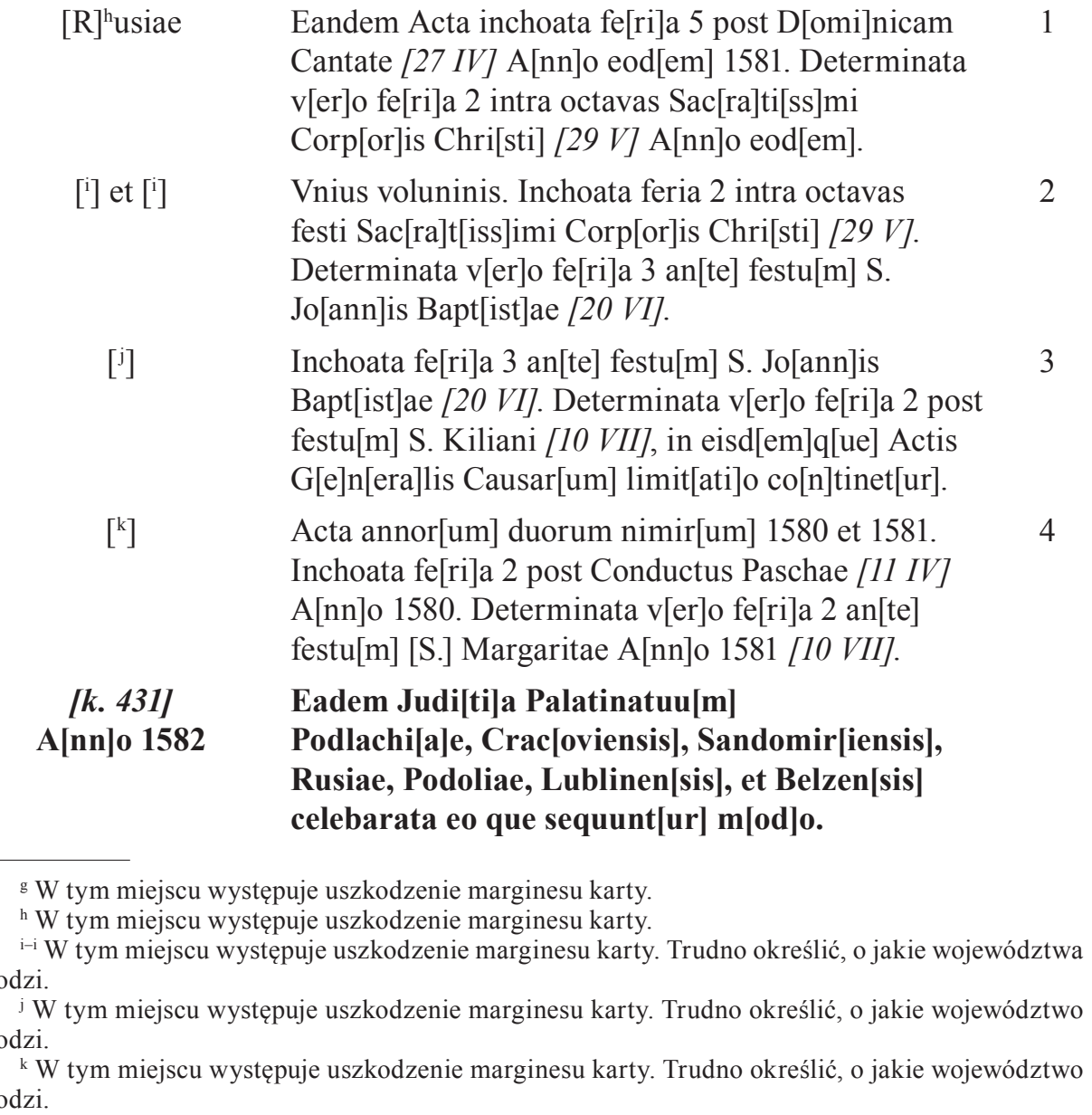


Podlachiae Inchoata fe[ri]a 2 post D. Conductus Paschae [23 IV]. Continuata v[er]o sabbato post D. Jubilate [11 V] A[nn]o eod[em] 1582.

Crac[oviensis] et

Vnius voluminis. Inchoata fe[ri]a 2 post D. Cantate [14 V]. Determinata v[er]o fe[ri]a 3 post D. Exaudi [29 V].

Rusiae

Inchoata fe[ri]a 4 post D. Exaudi [30 V].

Determinata v[er]o fe[ri]a 2 intra octavas festi

Sacratissimi Corp[or]is Chr[isti] [18 VI].

Podol[iae]

Vnius voluminis. Inchoata fe[ri]a 2 intra octavas

Lublin[ensis] et

Belzen[sis] festi Sacrati[ssi]mi Corp[or]is Chri[sti] [18 VI].

Determinata v[er]o sabbato in crasti[no] festi

$\mathrm{Sa}[\mathrm{n}]$ ctor[um] Petri et Pauli Ap[osto]lo[r]u[m] [30 VI], in eod[em] q[ue] voluminis fine limit[at]io $\mathrm{G}[\mathrm{e}] \mathrm{n}[\mathrm{era}] \mathrm{lis}$ Causar[u]m continet[ur].

\section{A[nn]o 1583}

\section{Judi[ti]a Palatinatuu[m] Crac[oviensis]}

Sandomir[iensis], Rusiae, Podoliae, Lublin[ensis], Belzen[sis] et Podlachiae celebratar[um] eo ordine.

Crac[oviensis]et Vnius voluminis. Inchoata feria 2 post D. Conductus [18 V].

Rusiae

Inchoata fe[ri]a 4 post D. Rog[ati]onu[m] [18 V].

Determinata v[er]o fe[ri]a 5 in octava festi Sac[ra]t[issi]mi Corp[or]is Chri[sti] [16 VI].

Podol[iae] Vnius voluminis. Inchoata fe[ri]a 5 in octava eiusd[em] festi [16 VI]. Determinata v[er]o fe[ri]a 4 Belzen[sis] post festum Visit[ati]onis B. M. V. [6 VII].

Podlachiae Inchoata fe[ri]a 4 post supra[scri]ptum festu[m] [6 VII]. Continuata v[er]o sabbato in vigilia festi S. Jacobi Ap[osto]li ${ }^{\text {n }}$, in eode[m]q[ue] volumine limit[ati]o G[e]n[era]lis ad futur[um] Trib[una]l[is] continet[ur].

${ }^{1}$ W tym miejscu występuje uszkodzenie marginesu karty.

${ }^{\mathrm{m}} \mathrm{W}$ tym miejscu występuje uszkodzenie marginesu karty.

${ }^{n}$ Błąd w datacji. Sabbato in vigilia festi S. Jacobi Apostoli przypada na 23 VII, natomiast najbliższa sabbata przypada ante festum S. Jacobi Apostoli, czyli na 24 VII.

${ }^{\circ} \mathrm{W}$ tym miejscu występuje uszkodzenie marginesu karty. 


\begin{tabular}{|c|c|c|}
\hline A[nn]o 1584 & $\begin{array}{l}\text { Juditia Trib[una]lia Palatinatuu[m] } \\
\text { Crac[oviensis], Sandomir[iensis], Rusiae, } \\
\text { Podoliae, Lublin[ensis], Belzen[sis] et Podlachiae } \\
\text { celebrabanto eo m[od]o. }\end{array}$ & \\
\hline Cracov[ie]n[sis] & $\begin{array}{l}\text { Inchoata fe[ri]a } 2 \text { post } \mathrm{D} \text {. Conductus Paschae }[9 \mathrm{IV}] \text {. } \\
\text { Determinata v[er]o fe[ri]a } 3 \text { post } \mathrm{D} \text {. Cantate }[1 \mathrm{~V}] \text {. }\end{array}$ & {$[1]^{\mathrm{p}}$} \\
\hline $\begin{array}{c}{[k .431 v]} \\
\text { Sandomir[iensis] }\end{array}$ & $\begin{array}{l}\text { Inchoata eadem fe[ri]a tertia }[1 \mathrm{~V}] \text {. Determinata } \\
\text { v[er]o feria sexta post D. Exaudi }[18 \mathrm{~V}]\end{array}$ & 2 \\
\hline Rusiae & $\begin{array}{l}\text { Inchoata fe[ri]a sexta ead[em] [18 V]. Determinata } \\
\text { v[er]o fe[ri] a s[e]c[un]da post festu[m] S. Viti }[18 \mathrm{VI}] \text {. }\end{array}$ & 3 \\
\hline $\begin{array}{l}\left.[\mathrm{P}]^{\mathrm{q}} \text { odol[iae }\right] \\
\text { Lublin[ensis et }] \\
\text { Belze[nsis }]\end{array}$ & $\begin{array}{l}\text { Vnius voluminis. Inchoata fe[ri] } 2 \text { post } \\
\text { sup[ra]scriptu[m] festum }[18 \text { VI]. Determinata } \\
\text { v[er] o fe[ri]a } 3 \text { post festum S. Kiliani [10 VII]. }\end{array}$ & 4 \\
\hline$[\mathrm{P}]^{\mathrm{r}}$ odlachiae & $\begin{array}{l}\text { Inchoata eade[m] fe[ri]a } 3 \text { post Kiliani }[10 \text { VII]. } \\
\text { Determinata v[er]o sabbato post fest[um] S. Jacobi } \\
{[28 \text { VII], ibid[em]q[ue] limit[ati]s g[e]n[era]lis }} \\
\text { continet[ur]. }\end{array}$ & 5 \\
\hline$[\mathrm{I}]^{\mathrm{s}} \mathrm{ns}[\mathrm{cri}] \mathrm{p}[\mathrm{ti}] \mathrm{onu}[\mathrm{m}]$ & $\begin{array}{l}\text { Annoru[m] } 1582 \text { et } 1583 \text { atq[ue] } 1584 \text { Jud[iti]oru[m] } \\
\text { sup[rascri]ptoru[m]. Inchoata fe[ri] } 2 \text { post } \\
\text { D. Conductus Paschae [23 IV] A[nn]o } 1582 \text {. } \\
\text { Determinata v[er]o sabbato p[o]s[t] festu[m] S. } \\
\text { Jacobi Ap[osto]li [28 VII] A[nn]o } 1584 \text {. }\end{array}$ & 6 \\
\hline [Ann] o 1585 & $\begin{array}{l}\text { Judi[ti]a Tribunalis Regni Crac[oviensis], } \\
\text { Sandomir[iensis], Rusiae, Podoliae, Lublinen[sis], } \\
\text { Belzen[sis] et Podlachiae Palatinatuu[m] } \\
\text { celebrata quoru[m] Acta sequu[n]t[ur] eo modo. }\end{array}$ & \\
\hline $\begin{array}{l}\text { [Cracoviensis] }^{\mathrm{u}} \text { et } \\
\text { San[domir]ien[sis] }\end{array}$ & $\begin{array}{l}\text { In uno volumini. Inchoata fe[ri]a } 2 \text { post D. } \\
\text { Conduct[us] Paschae [29 IV]. Determinata } \\
\text { v[er]o fe[ri]a } 6 \text { post D. Jubilate }[17 \mathrm{~V}] \mathrm{A}[\mathrm{nn}] \mathrm{o} 1585 .\end{array}$ & 1 \\
\hline [Rusiae] $]^{v}$ & $\begin{array}{l}\text { Inchoata fe[ri]a } 6 \text { post D. Jubilate. Determinata } \\
\text { v[er]o fe[ri]a } 6 \text { post D. Exaudi. }\end{array}$ & 2 \\
\hline \multicolumn{3}{|c|}{ 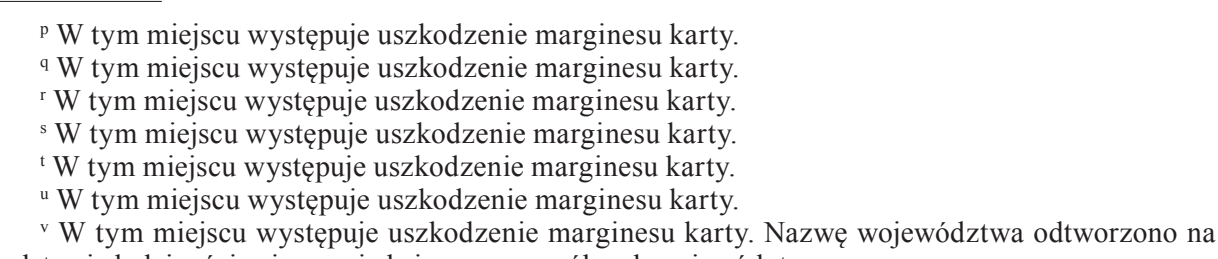 } \\
\hline
\end{tabular}


[Lublinensis] ${ }^{\mathrm{w}}, \quad$ Vnius voluminis. Inchoata videlicet fe[ri]a 6 post

Belz[ensiset][P]odoliae D. Exaudi [7 IV]. Determinata v[er]o fe[ri]a 6 post festu[m] Visit[ati]onis B. Mariae V. [5 VII].

[Pod] ${ }^{x}$ lachiae Inchoata sabbato post sup[rascri]ptum festu[m]

Mariae [6 VII]. Determinat[a] v[er]o sabbato post festu[m] Divisio[n]is Ap[osto]lor[um] [20 VII], ibidemq[ue] limit[at]o g[e]n[er]alis [c]ontinet[ur].

\begin{tabular}{|c|c|}
\hline [Anno 1586] ${ }^{\mathrm{y}}$ & $\begin{array}{l}\text { Judi[ti]a Trub[una]lia omniu[m] palatinatuum } \\
\text { sup[rascri]ptor[um] sunt celebrata eo m[od]o. }\end{array}$ \\
\hline$\left[{ }^{2}\right]$ & $\begin{array}{l}\text { Inchoata fe[ri]a } 2 \text { post } \mathrm{D} \text {. Conductus Paschae } \\
{[14 \mathrm{IV}] \text {. Determinata [ver]o fe[ri]a tertia post } \mathrm{D} \text {. }} \\
\text { Cantate }[6 \mathrm{~V}] \text {. }\end{array}$ \\
\hline [aа] & $\begin{array}{l}{[\mathrm{I}] \text { nchoata fe[ri]a } 3 \text { post } \mathrm{D} \text {. Cantate }[6 \mathrm{~V}] \text {. }} \\
\text { Determinata v[er]o fe[ri]a } 4 \text { post D. [T]rinit[at]is } \\
{[4 \mathrm{VI}] \text {. }}\end{array}$ \\
\hline
\end{tabular}

[ab] [In]choata ead[em] fe[ri]a q[ua]rta [4 VI].

Determinata v[er]o fe[ri]a 4 post festu[m] S. Petri et [Pauli] [2 VII].

[k. 432] In vno volumine contenta. Inchoata

Podol[iae], fe[ri]a qvinta $\mathrm{p}[\mathrm{o}] \mathrm{s}[\mathrm{t}]$ festu[m] supras[cri]ptum

Lublin[ensis] et [3 VII]. Determinata v[er]o fe[ri]a 5 in vigilia festi S.

Belzen[sis] Jacobi Ap[osto]li [24 VII].

Podlachiae Inchoata fe[ri]a sexta ip[s]o die festi S. Jacobi Ap[osto]li [25 VII]. Determinata v[er]o fe[ri] a tertia [29 VII] in vigilia[31 VII] festi

S. Petri in Vincul[is] ${ }^{\text {ac }}$, ibid[em] co[n]tinet[ur] limit[at]o causar[um] g[e]n[era]lis.

Inscriptionu[m] annor[um] superioru[m] duor[um] 1585 et 1586 . Inchoata fe[ri]a 3 post $\mathrm{D}$. Conductus Paschae [30 IV] A[nn]o 1585.. Determinata v[er]o fe[ri]a 3 post festu[m] S. Petri in Vinculis [5 VIII] A[nn]o 1586.

\footnotetext{
${ }^{\mathrm{w}} \mathrm{W}$ tym miejscu występuje uszkodzenie marginesu karty.

${ }^{\mathrm{x}} \mathrm{W}$ tym miejscu występuje uszkodzenie marginesu karty.

${ }^{\mathrm{y}} \mathrm{W}$ tym miejscu występuje uszkodzenie marginesu karty. chodzi.

${ }^{\mathrm{z}} \mathrm{W}$ tym miejscu występuje uszkodzenie marginesu karty. Trudno określić, o jakie województwo

aa W tym miejscu występuje uszkodzenie marginesu karty. Trudno określić, o jakie województwo chodzi. chodzi.

${ }^{a b}$ W tym miejscu występuje uszkodzenie marginesu karty. Trudno określić, o jakie województwo

ac Błąd w datacji. Feria tertia ante festum S. Petri in Vinculis przypada na 29 VII, natomiast in vigilia festi S. Petri in Vinculis przypada na 31 VII.
} 


\section{A[nn]o $1589 \quad$ Judi[ti]a Palatinatuu[m] praedictor[um] o[mnio]rum celebrata eo ordine.}

Cracov[ie]n[sis] Inchoata fe[ria] 2 post D. Conductus Paschae [10 IV]. Determinat[a] v[er]o fe[ri]a 4 post D. Jubilate $[26 \mathrm{IV}]$.

Sandomir[iensis] Inchoata sup[rascri]pta fe[ri]a 4 [26 IV].

Det[er]minata v[er]o fe[ri]a 2 post Trinitatis [29 V].

Rusiae

Inchoata ead[em] fe[ri]a 2 post Trinitatis [29 V].

Determinata v[er]o fe[ri]a 4ta post festu[m] S. Vitti [21 VI].

Podol[iae], In vno volumine. Inchoata fe[ri]a ead[em] 4 post Viti

Lublin[ensis] et [21 VI]. Determinata v[er]o fe[ri]a 2 post festum $\mathrm{S}$.

Belzen[sis] Kiliani [10 VII].

Podlachiae Inchoata fe[ri]a 3 post festum S. Kiliani [11 VII].

\section{A[nn]o $1590 \quad$ Omnium eor[un]dem Palatinatuu[m] judi[ti]a celebrata eo $\mathbf{m}[\mathbf{o d}] \mathbf{0}$.}

Crac[oviensis]

Inchoata feria $\mathrm{s}[\mathrm{e}] \mathrm{c}[\mathrm{u}]$ nda post $\mathrm{D}$. Conductus

Paschae [30 IV]. Determinat[a] v[er]o fe[ri]a 4 post

D. Cantate [23 V].

Sandomir[iensis]

Inchoata ead[em] fe[ri]a 4 [23 V]. Determinata $\mathrm{v}$ [er]o fe[ri]a 2 post fest[um] T[r]ini[ta]tis [18 VI].

Rusiae Inchoata ead[em] fe[ri]a 2 [18 VI]. Determinata $\mathrm{v}$ [er]o fe[ri]a 4 post festum S. Margaritae [18 VII].

Podol[iae], In vno volumine. Inchoata fe[ri]a 4 post festu[m] v[er]o fe[ri]a 6 ip[s]o die Bartholom[aeum] [24 VIII].

Podlachiae Inchoat[a] ead[em] fe[ri]a 6 [24 VIII]. Det[er]minat[a] v[er]o fe[ri]a 3 post Egidii [4 IX]. Ac ibi limi[ta]to $\mathrm{g}[\mathrm{e}] \mathrm{n}[\mathrm{era}] \mathrm{lis}$.

Ex offitio 


\begin{tabular}{|c|c|}
\hline Ins[cri]p[ti]onu[m] & $\begin{array}{l}\text { et recognitionu[m] annor[[um] duor[um]. Inchoat[a] } \\
\text { fe[ri]a } 2 \text { post Conductus }[10 \mathrm{IV}] \mathrm{A}[\mathrm{nn}] \mathrm{o} 1589 . \\
\text { Deter[mi]nata v[er]o fe[ri]a } 3 \text { p[o]s[t] festu[m] Egiii } \\
{[4 I X] \text { A[nn]o } 1590 .}\end{array}$ \\
\hline $\begin{array}{c}{[k .432 v]} \\
{[\text { Anno] 1591 }}\end{array}$ & $\begin{array}{l}\text { Crac[oviensis], Sandomiri[ensis], Kiiowie } \\
\text { et Rusiae atq[ue] alior[um] expedita Judi[ti]a eo } \\
\text { ordine. }\end{array}$ \\
\hline Crac[oviensis] & $\begin{array}{l}\text { Inchoata fe[ri]a } 2 \text { post } \mathrm{D} \text {. Conductus Paschae } \\
{[22 \mathrm{IV}] \text {. Determinat[a] v[er]o fe[ri]a } 2 \text { post } \mathrm{D} \text {. }} \\
\text { Cantate }[13 \mathrm{~V}] \text {. }\end{array}$ \\
\hline Sandomir[iensis] & $\begin{array}{l}\text { Inchoata ead[em] fe[ri]a } 2[13 \mathrm{~V}] \text {. Determinata } \\
\text { v[er]o fe[ri]a } 4 \text { post d[ie] festi Sa[n]ctissimae } \\
\text { Trini[ta]tis }[12 \text { VI]. }\end{array}$ \\
\hline Rusiae & $\begin{array}{l}\text { Inchoata fe[ri]a } 6 \text { in crast[in]o festi } \\
\text { Sac[ra]ti[ss]imi Corp[or]is Chri[sti] [14 VIJ. } \\
\text { Determinata v[er]o fe[ri]a } 4 \text { post Margaritae } \\
\text { [17 VII]. }\end{array}$ \\
\hline $\begin{array}{l}\text { Podol[iae], } \\
\text { Lublin[ensis] et } \\
\text { Belzen[sis] }\end{array}$ & $\begin{array}{l}\text { Vnius voluminis. Inchoata fe[ri]a } 2 \text { post festu[m] S. } \\
\text { Laurentii }[12 \text { VIII]. Determinata v[er]o fe[ri]a } 6 \text { in } \\
\text { vigilia festi S. Bartholom[aei] [23 VIII]. }\end{array}$ \\
\hline Podlachiae & $\begin{array}{l}\text { Inchoata fe[ri]a } 2 \text { post festu[m] S. Bartholomaei } \\
\text { [26 VIII]. Determinata v[er]o fe[ri]a } 3 \text { post festu[m] } \\
\text { S. Egidii [3 IX]. }\end{array}$ \\
\hline $\begin{array}{l}\text { Ex } \\
\text { offi[ti]o [c]ausar[um] } \\
\text { expeditar[um] }\end{array}$ & $\begin{array}{l}\text { Inchoata feria qvarta post D. Conductus Paschae } \\
{[24 \mathrm{IV}] \text {. Determinata v[er]o fe[ri]a } 6 \text { post }} \\
\text { festum S. Egidii }[6 I X] \text {, in eisd[em]q[ue] Act[is] } \\
\text { limit[ati]o causar[um] g[e]n[era]lis continet[ur]. }\end{array}$ \\
\hline [Ann]o 1592 & $\begin{array}{l}\text { Palatinatum Crac[oviensis], Sandomir[ie]n[sis], } \\
\text { Kiioviensis et Rusiae Judi[ti]a absolut[o] eo } \\
\text { m[od]o. }\end{array}$ \\
\hline ak $[\mathrm{Cr}] \mathrm{ac}[$ oviensis] & $\begin{array}{l}\text { Inchoata fe[ri]a } 2 \text { post } \mathrm{D} \text {. Conductus Paschae }[6 \mathrm{IV}] \text {. } \\
\text { Determinata v[er]o fe[ri]a } 2 \text { post D. Exaudi }[11 \mathrm{~V}] \text {. }\end{array}$ \\
\hline [S]and[omi]r[ie]n[sis] & $\begin{array}{l}\text { Inchoata ead[em] fe[ri]a } 2 \text { supra[scrip]ta }[11 \mathrm{~V}] \\
\text { Determinat[a] v[er]o fe[ri]a } 5 \text { in crast[in]o festi S. } \\
\text { Jo[ann]is Bapt[ist]ae }[25 \mathrm{VIJ} \text {. }\end{array}$ \\
\hline
\end{tabular}

\footnotetext{
aj W tym miejscu występuje uszkodzenie marginesu karty.

ak W tym miejscu występuje uszkodzenie marginesu karty.

al W tym miejscu występuje uszkodzenie marginesu karty.
} 
am[R]usiae Inchoata fe[ri]a 2 post festum Visit[ati]onis B. V. M. [6 VII]. Determinata v[er]o fe[ri]a 6 in vigilia festi S. Jacobi [24 VII].

$[\text { Kiioviensis }]^{\text {an }}$

Sub eode[m] Trib[una]li expeditar[um]. Inchoata

fe[ri]a 2 post D. Conductus Paschae [6 IV].

Determinata v[er]o fe[ri]a 6 in Vigilia festi S. Jacobi [24 VII].

[Inscrip ${ }^{\mathrm{a} o t i o n u}[\mathrm{~m}]$ et recognitionum annor[um] duor[um]. Inchoata fe[ri]a 2 post D. Conductus Paschae [22 IV] $\mathrm{A}[\mathrm{nn}] \mathrm{o}$ 1591. Determinata v[er]o fe[ri]a 6 in vigilia festi S. Jacobi Ap[osto]li [24 VII] A[nn]o 1592.

[Anno 1593] [J]udi[ti]a Palatinatuu[m] Rusiae, Wolhiniae, Podoliae, Lublin[ensis], Belzen[sis] et Podlachiae su[n]t [k. 433] celebrata eo ordine.

Rusiae

Inchoata fe[ri]a 2 post $\mathrm{D}$. Conductus Paschae [26 IV]. Determinata v[er]o fe[ri]a 6 post festa Solemnia Pentecostes [11 VI].

Podoliae et In vno volumine contenta. Inchoata fe[ri]a 5 an[te]

Lublin[ensis] festu[m] S. Perti in Vincul[is] [29 VII]. Determinata v[er]o fe[ri]a 2 in Vigilia festi S. Bartholom[aei] [23 VIII].

Belzen[sis] et In vno volumine. Inchoata fe[ri]a 3 ip[s]o die S.

Podlachiae Bartholomaei [24 VIII]. Determinata v[er]o fe[ri]a 5 in crastino festi Nativi[ta]tis B. M. Virgin[is] [9 IX], ibid[em]q[ue] limitatio g[e]n[era]lis continet[ur].

Offi[ti]i Causar[um] eiusd[em] Jud[iti]ii Trib[una]lis. Inchoata fe[ri]a 2 post D. Conductus Paschae [26 IV]. Determinata v[er]o fe[ri]a 5 in crastino festi Nati[vi]tatis B. M. V.

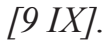

A[nn]o 1594

Juditia Palatinatuu[m] Podlachiae, Braclavien[sis], Crac[oviensis] et Sandomir[iensis] su[n]t celebrata eo ordine.

Podlachiae Inchoata fe[ri]a 2 post D. Conductus Paschae [18 IV]. Determinata v[er]o fe[ri]a 6 post festum Solemnia Pentecostes [3 VI].

\footnotetext{
${ }^{a m} \mathrm{~W}$ tym miejscu występuje uszkodzenie marginesu karty.

an W tym miejscu występuje uszkodzenie marginesu karty.

ao $\mathrm{W}$ tym miejscu występuje uszkodzenie marginesu karty.
} 
Crac[oviensis] Inchoata fe[ri]a 5 in octava festi

Sac[ra]t[iss]imi Corp[or]is Chri[sti] [16 VI].

Determinata v[er]o fe[ri]a 6 post festu[m] S. Jacobi [29 VII].

Sandomir[iensis] Inchoata fe[ri]a s[e]c[u]nda ip[s]o die festi S. Petri in Vinculis [1 VIII]. Determinata v[er]o fe[ri]a 5 in crast[in]o festi S. Bartholomaei [25 VIII].

Ex offi[ti]o causar[um] eod[em] Trib[una]li expeditar[um]. Inchoata fe[ri]a 3 post D. Conductus Paschae [19 IV]. Determinata v[er]o sabbato post fest[um] S. Bartholom[aei] [27 VIII].

Ins[cri]p[ti]onum

et reconi[ti]onu[m] variar[um] annor[um] duor[um]. Inchoata $\mathrm{f}$ [eria] 2 da post $\mathrm{D}$. Conductus Paschae A[nn]o 1593 [26 IV]. Determinata v[er]o sabbato post festu[m] S. Bartholom[aeum] A[nn]o 1594 [27 VIII]

\section{A[nn]o 1595 Juditia Palatinatuu[m] Sandomir[iensis],} Kiiovien[sis], Rusiae et Wolhiniae su[n]t celebrata eo m[od] 0 .

Sandomir[iensis] Inchoata fe[ri]a 2 post D. Conductus Paschae [3 IV]. [1] ${ }^{\text {ar }}$ Determinata fe[ri]a 2 post D. Exaudi [8 V].

[k. 433v]

Rusiae

Ex offi[iti]o

A[nn]o 1596

Podoliae
Inchoata fe[ri]a 6 post D. Sac[ra]ti[ssi]mae

Trinit[at]is $[26 \mathrm{~V}]$. Determinata v[er]o fe[ri]a 6 in crastino festi S. Petri et Pauli [30 VI].

causar[um] in eode[m] Trib[una]li expeditar[um]. Inchoata sabbato $\mathrm{p}[\mathrm{o}] \mathrm{s}[\mathrm{t}] \mathrm{D}$. Conductus Paschae [8 IV]. Determinata v[er]o fe[ri]a 5 ip[s]o die festi S. Laurentii Marty[ri]s [10 VIII].

Judi[ti]a Trib[una]lia Palatinatuu[m] Podoliae, Lublin[ensis], Belzen[sis], Podlachiae, Braclavien[sis], Crac[oviensis], Sandomir[iernsis] et Kiiovie[nsis] celebrata eo $\mathbf{m}[\mathbf{o d}] \mathbf{o}$.

Inchoata fe[ri]a $2 \mathrm{p}[\mathrm{o}] \mathrm{s}[\mathrm{t}]$ Dominica[m] Conductus Paschae [22 IV]. Determinata v[ero] fe[ri]a 2 post D. Jubilate $[6 \mathrm{~V}]$.

\footnotetext{
ap W tym miejscu występuje uszkodzenie marginesu karty.

aq W tym miejscu występuje uszkodzenie marginesu karty.

${ }^{\text {ar }} \mathrm{W}$ tym miejscu występuje uszkodzenie marginesu karty.
} 
Lublin[ensis] [In]choata fe[ri]a 2 post eand[em] Dominic[am] [6 V]. Determinat[a] v[er]o fe[ri]a 5 post D. Exaudi [30 V].

Belzen[sis] Inchoata ead[em] fe[ri]a 5 post eadn[em] Dominica[m] [30 V]. Determinat[a] v[er]o fe[ri]a 4 intra octavas Sac[ra]ti[ssi]mi Corp[or]is Chri[sti] [19 VI].

Podlachiae Inchoata fe[ri]a 4 intra octavas eiusdem festi [19 VI]. Determinata v[er]o fe[ri]a 2 ip[s]o die S. Kiliani [8 VII].

$[\mathrm{C}]^{\text {as }}$ rac[oviensis] Inchoata fe[ri] a 6 pridie festi S. Margaritae [12 VII]. Determinata v[er]o fe[ri]a 3 post Laurentii [13 VIII].

$[\mathrm{Sa}]^{\text {at }}$ ndomir[iensis] Inchoata fe[ri]a 4 in crast[in]o festi

Transfigur[ati]onis D[o]m[ini] [7 VIII]. Determinata v[er]o fe[ri]a 4 post Bartholomaei [28 VIII].

Causar[um] per hoc id[em] Tribunal expeditar[um]. Inchoant[ur] fe[ri]a 2 p[o]s[t] D. Conductus Paschae [22 IV]. Determinata v[er]o sabbato pridie festi S. Egidii [31 VIII], ibide[m]q[ue] limit[ati]o causar[um] $\mathrm{g}[\mathrm{e}] \mathrm{n}[\mathrm{era}] \mathrm{lis}$ contin[e]t[ur].

[Anno 1597] Jud[iti]a eadem Trib[una]lia Palatinatuu[m] Rusiae, Wolhiniae, Podoliae, Lublinen[sis] et Belzen[sis] su[n]t celebrata ordine sequenti.

[Rusiae et Wolhinie] $]^{\text {au }}$ Inchoata fe]ri]a 2 post D. Conductus Paschae [14 VI]. Determinat[a] fe[ri] $2^{[9 \mathrm{VI}]}$ in crast[in] $\mathrm{o}^{[6 \mathrm{VI}]}$ festi Solemnis Sacrati[ssi]mi Corp[or]is Chri[sti].

[k. 434] Vnius voluminis. Inchoata fe[ri]a sexta ipso die festi Podol[iae], S. Jacobi Ap[osto]li [25 VII].

Lublin[ensis] et

Belzen[sis]

Ins[cri]p[ti]onum

et recognitionu[m] annoru[m] sup[er]ioru[m] nempe 1595 et 1596 atq[ue] 1597. Inchoata fe[ri]a 3 post D. Conductus Paschae [4 IV] A[nn]o 1595. Determinata v[er]o sabbato an[te] festum S. Egidii [30 VIII] $\mathrm{A}[\mathrm{nn}] \mathrm{o} 1597$.

as W tym miejscu występuje uszkodzenie marginesu karty.

${ }^{\text {at }} \mathrm{W}$ tym miejscu występuje uszkodzenie marginesu karty. 
Causaru[um]

A[nn]o 1598

Podlachiae

Rusiae

Ex offi[ti]o

Inscriptionu[m]

ex off[it]io eiusd[em] Trib[una]lis. Inchoata fe[ri]a 3

post D. Conductus Paschae [15 VI]. Determinata

v[er]o sabbato an[te] Egidii [30 VIII], ibidemq[ue]

limit[ati]o g[e]n[era]lis continet[ur].

\section{Juditia Trib[una]lia Palatinauu[m] Podlachiae,} Braclavien[sis], Crac[oviensis], Sandomir[iensis], Rusiae et Wolhiniae su[n]t expedita eo m[od]o.

$\begin{array}{cl} & \text { [30 III]. Determinata v[er]o fe[ri]a } 3 \text { post D. } \\ & \text { Rogationu[m] [28 IV]. } \\ \text { Cracov[ie]n[sis] } & \text { Inchoata fe[ri]a } 3 \text { post D. Exaudi [5 V]. Determina } \\ & \text { v[er]o fe[ri]a } 6 \text { post festu[m] S. Marcellini [5 VI]. } \\ \text { Sandomir[iensis] } & \text { Inchoata eade[m] fe[ri]a } 6 \text { post spu[ra]s[cri]ptum } \\ & \text { festum [5 VI]. Determinata v[er]o fe[ri]a } 5 \text { in } \\ & \text { crast[in]o festi S. Kiliani [9 VII]. } \\ \text { Rusiae } & \text { Inchoata fe[ri]a } 5 \text { in crastino festi S. Mariae } \\ & \text { Magdale[nae] [23 VII]. Determinata v[er]o fe[ri]a } 4 \\ & \text { post festu[m] S. Laure[n]tii Martyr[is] [12 VIII]. } \\ \text { Ex offi[ti]o } & \text { causar[um] eiusdem Trib[una]lis. Inchoata fe[ri]a 3 } \\ & \text { post D. Conductus Paschae [31 III]. Determinata } \\ & \text { v[er]o fe[ri]a } 5 \text { post festu[m] S. Bartholom[aeum] } \\ & \text { Ap[osto]li [27 VIII], ibidemq[ue] limi[tatio] } \\ & \text { causar[um] g[e]n[era]lis continet[ur]. }\end{array}$

et recognitionu[m] variar[um] sub eodem

Trib[una]li. Inchoata fe[ri]a 3 post D. Conductus

Paschae [31 III]. Determinata v[er]o fe[ri]a 5 post festu[m] S. Bartholomaei [27 VIII].

Przy oddaniu Xiąg pieniedzy zadnych nieoddano Je[g]o M[ości] Panv Pisarzowi

Nicolaus Brodowskij

Notarius Terr[estr]is

Lublinen[sis]

manu $\mathrm{p}[\mathrm{ro}] \mathrm{p}[\mathrm{ria}]$
Chr[ist]oph[or]o Wronowski

Camerar[ius] Terrestris

Lubli[nensis]
Stanislaus [Rączka]

Piczko[wski]Camerarius

Terrestris Lubliniensis

av W tym miejscu występuje uszkodzenie marginesu karty.

aw $\mathrm{W}$ tym miejscu występuje uszkodzenie marginesu karty.

ax W tym miejscu występuje uszkodzenie marginesu karty.

ay $\mathrm{W}$ tym miejscu występuje uszkodzenie marginesu karty. 